\title{
IMPLEMENTASI PROGRAM KELUARGA HARAPAN TERHADAP PEMENUHAN HAK SOSIAL WARGA LANSIA MISKIN (STUDI DI KECAMATAN JEBRES KOTA SURAKARTA)
}

Oleh :

\author{
Barjo Wahyu Hidayat, M Hendri Nuryadi, Rusnaini \\ Program Studi PPKn FKIP Universitas Sebelas Maret Surakarta \\ e-mail: barjowhidayat@gmail.com
}

\begin{abstract}
The purpose of this study is to (1) knowhow the implementation of PKH policies towards the fulfillment of social rights of poor elderly citizens. (2) to find out the factors that affect the implementation of PKH policies.

This study used descriptive qualitative research. Sources of data used are informants, events or activities and documents. The sampling technique is purposive sampling. Techniques of the data collection and compilation of data were done by interviews, observation and document analysis. The researcher used data triangulation and triangulation methods to obtain valid data. While the techniques of analyzing the data using interactive models are: (1) data collection (2) data reduction (3) data presentation and (4) drawing conclusions. This research procedure follows the following steps: (1) pre-field, (2) field implementation, (3) field analysis, and (4) preparation of the research report.

Based on the results of the research can be concluded that: (1) Implementation of PKH in the fulfillment of the social rights of poor elderly people in Jebres District has been run in accordance with the SOP in the PKH guidebook, These activities include: Targetting, Socialization, Grants, group meetings, assistance and commitment verification. (2) There are supporting and inhibiting factors in the implementation of PKH in Jebres Sub-district, Supporting Factors: Resources, Public Support, and Characteristics of implementing agents, while the constraining factors: Communication, Disposition. and goals.
\end{abstract}

Keywords :Implementation of policy, Family Hope Program, social rights of poor elderly citizens 


\begin{abstract}
ABSTRAK
Tujuan penelitian ini adalah untuk (1) Untuk mengetahui bagaimana implementasi Program Keluarga Harapan dalam memenuhi hak warga lansia miskin di Kecamatan Jebres Kota Surakarta. (2) Untuk mengetahui faktor-faktor yang mempengaruhi implementasi PKH dalam memenuhi hak warga lansia miskin di Kecamatan Jebres, Kota Surakarta.

Penelitian ini menggunakan bentuk penelitian kualitatif yang bersifat deskriptif. Sumber data yang digunakan adalah informan, peristiwa atau aktivitas dan dokumen. Teknik pengambilan sampel adalah purposive sampling. Teknik pengumpulan data dan penyusunan data melalui wawancara, observasi dan analisis dokumen. Peneliti menggunakan trianggulasi data dan trianggulasi metode untuk mendapatkan data yang valid. Sedangkan teknik analisis data menggunakan model interaktif yaitu : (1) pengumpulan data (2) reduksi data (3) sajian data dan (4) penarikan kesimpulan. Prosedur penelitian ini mengikuti langkah-langkah : (1) pra lapangan, (2) pelaksanaan lapangan, (3) analisis lapangan, dan (4) penyusunan laporan penelitian.

Berdasarkan hasil penelitian dapat ditarik kesimpulan : (1) Implementasi PKH dalam pemenuhan hak sosial warga lansia miskin di Kecamatan Jebres sudah berjalan sesuai dengan SOP dalam buku pedoman $\mathrm{PKH}$, kegiatan tersebut meliputi: Targetting, Sosialisasi, Pemberian bantuan, pertemuan kelompok, pendampingan dan verifikasi komitmen (2) Ada faktor pendukung dan penghambat dalam implementasi PKH di Kecamatan Jebres, Faktor pendukung: Sumber Daya, Dukungan Publik, dan Karakteristik agen pelaksana, sementara faktor penghambat: Komunikasi, Disposisi. dan sasaran.
\end{abstract}

Kata Kunci : Implementasi Kebijakan, Program Keluarga Harapan, Hak sosial warga lansia miskin. 


\section{PENDAHULUAN}

Kemiskinan merupakan masalah kompleks dan mendesak untuk diatasi. Masalah kemiskinan memerlukan strategi ekstra untuk menanggulangi, menurunkan, dan mengentaskannya.

Ancaman kemiskinan dapat berdampak luas, bahkan merupakan ancaman pada seluruh lini kehidupan berbangsa dan bernegara baik di lini ekonomi, ideologi, stabilitas politik, lingkungan, keamanan, dan sosial budaya.

Masalah kemiskinan dalam pembangunan di Indonesia merupakan salah satu masalah utama yang ditandai oleh masih besarnnya jumlah penduduk miskin, pengangguran, keterbelakangan, dan keterpurukan. Menurut Suharyanto yang dikutip dalam Syawie (2011: 217) menjelaskan bahwa kemiskinan merupakan kondisi seseorang atau sekelompok orang yang tidak mampu memenuhi hak-hak dasarnya untuk mempertahankan dan mengembangkan kehidupan yang bermartabat.

Kemiskinan hampir menjadi permasalahan di semua negara, baik di negara maju maupun di negara berkembang dengan tingkat permasalahan yang berbeda-beda. Di Indonesia sebagai salah satu negara berkembang, kemiskinan merupakan suatu permasalahan penting dan sangat serius, karena kemiskinan membuat banyak masyarakat Indonesia mengalami kesulitan dalam memenuhi kebutuhan dasar hidupnya (sandang, pangan, dan papan).

Selain itu menurut Suharto (1997) dalam Sjafari (2014: 10) berpendapat bahwa kemiskinan mempunyai dampak negatif yang bersifat menyebar (multiplier effects) terhadap tatanan masyarakat secara menyeluruh. Berbagai peristiwa konflik di tanah air yang terjadi sepanjang krisis ekonomi misalnya menunjukkan bahwa ternyata persoalan kemiskinan bukanlah semata-mata memengaruhi ketahanan ekonomi yang ditampilkan oleh rendahnya daya beli masyarakat, melainkan pula memengaruhi ketahanan sosial masyarakat dan ketahanan nasional.

Indonesia merupakan bagian dari negara kesejahteraan (welfare state). Maka segala kebijakan yang dibuat Pemerintah harus diarahkan untuk meningkatkan kesejahteraan sosial warga negaranya. Selain itu sebagai negara kesejahteraan juga memiliki kewajiban untuk memberikan perlindungan sosial kepada kelompok rentan dalam hal ini warga lanjut usia sehingga dapat mempertahankan kondisi kesejahteran lansia dalam rangka mendukung terwujudnya kesejahteraan sosial bagi warga lanjut usia.

Kehidupan lansia di Indonesia dinilai masih sangat memprihatinkan baik di mata dunia maupun di dalam Indonesia sendiri. Secara global pada tahun 2015, Indonesia menduduki peringkat 74 dari 96 negara dalam Indeks AgeWatch Global oleh HelpAge International. Performa terbaik Indonesia ada pada tingkat keselamatan lansia dalam bepergian $(89 \%)$ dan hubungan dengan lingkungan sosial sekitar (78\%). Namun, Indonesia memiliki persentase paling rendah pada ketersediaan dana pensiun $(8,1 \%)$. Di Indonesia sendiri, data Statistik Penduduk Lanjut Usia di Indonesia oleh BPS 2015 menyatakan bahwa 
dari sekitar 21 juta jiwa lansia $(8,5 \%$ dari populasi penduduk) ada $9,55 \%$ lansia terlantar dan 23,52\% lansia hampir terlantar. Sebanyak 46,53\% lansia masih bekerja dengan separuh lebih dari mereka hanya memperoleh upah kurng dari $\mathrm{Rp}$ $1.000 .000,00 /$ bulan. Selain itu, $45,14 \%$ lansia di Indonesia berada di rumah tangga dengan status ekonomi rendah dan hanya $11,08 \%$ dari jumlah rumah tangga lansia memiliki jaminan sosial.

Lansia memiliki hak untuk memperoleh kehidupan yang wajar guna meningkatkan kualitas kesejahteraan hidup mereka. Sebagaimana yang tercantum dalam Undang-Undang Dasar 1945 pasal 27 ayat 2 yang berbunyi : "Tiap-tiap warga negara berhak atas pekerjaan dan penghidupan yang layak bagi kemanusiaan". Lansia juga merupakan bagian dari warga negara yang harus dipenuhi hak-haknya. Selanjutnya dalam Undang-Undang Dasar 1945 pasal 28 I ayat 2 yang isinya bahwa "Setiap orang berhak bebas dari perlakuan yang bersifat diskriminatif atas dasar apapun dan berhak mendapat perlindungan terhadap perlakuan yang bersifat diskriminatif itu". Hal ini menandakan bahwa lansia mempunyai harkat, martabat dan kedudukan yang sama di dalam masyarakat dan di suatu negara.

Pemerintah dalam memenuhi hak warga lansia miskin tersebut membuat sebuah kebijakan yaitu Program Keluarga Harapan (PKH) lansia. Dimana dengan adanya program ini diharapkan dapat meningkatkan taraf kesejahteraan warga lansia miskin. Pada kenyataannya program ini dirasa masih belum efektif dimana dalam kurun waktu lima tahun terakhir penurunaan kemiskinan Indonesia berjalan melambat. Sementara tingkat kemiskinan di Kota Surakarta juga tergolong masih tinggi yaitu mencapai 196.423 jiwa pada tahun 2016 dan $55 \%$ penduduk lansia berada pada status ekonomi terendah.

Berdasarkan latar belakang di atas penulis tertarik untuk melakukan penelitian guna mengetahui bagaimana implementasi kebijakan PKH di kecamatan Jebres. Tujuan penelitian ini adalah untuk mengetahui bagaimana implementasi pkh lansia di Kecamatan Jebres dalam memenuhi hak sosial warga lansia miskin dan mengetahui faktor-faktor yang mempengaruhi implementasi tersebut.

\section{METODE PENELITIAN}

Jenis penelitian yang digunakan adalah metode penelitian deskriptif dengan pendekatan kualitatif. Bogdan dan Taylor (1975) dalam Moleong (2012: 3) mendefinisikan metodologi kualitatif sebagai "prosedur penelitian yang menghasilkan data deskriptif berupa kata-kata tertulis atau lisan dari orang-orang dan perilaku yang dapat diamati". Lokasi penelitian di Kecamatan jebres. Data primer diperoleh dengan wawancara. Data skunder diperoleh dengan mencari dokumen-dokumen sesuai dengan tema penelitian. Adapun yang menjadi fokus penelitian adalah: (1) Implementasi PKH lansia di Kecamatan Jebres dan (2) Faktorfaktor yang mempengaruhi impleementasi PKH lansia di Kecamatan Jebres. Analisis data menggunakan metode analisis model 
interaktif yang menurut Miles \& Hubberman dalam Sugiyono (2011: 247) ada tahapan yang harus dilalui yakni: reduksi data, penyajian data, dan menarik kesimpulan.

\section{HASIL DAN PEMBAHASAN}

1. Implementasi PKH lansia di Kecamatan Jebres

Program Keluarga Harapan

Lansia merupakan program perlindungan sosial yang dibuat oleh kementerian Sosial dalam rangka memutus rantai kemiskinan. Lansia yang berhak mendapatkan bantuan PKH adalah lansia yang telah berusia 70 tahun dan masuk ke dalam daftar keluarga penerima manfaat. $\mathrm{PKH}$ merupakan kebijakan negara yang digunakan sebagai instrumen pemenuhan Hak Asasi Manusia yaitu hak sosial, dimana sesuai dengan bunyi pasal 34 ayat (2) UUD 1945 dimana "negara mengembangkan sistem jaminan sosial bagi seluruh rakyat dan memberdayakan masyarakat yang lemah dan tidak mampu sesuai dengan martabat kemanusiaan". Hal tersebut sejalan dengan konsep fungsi pokok PKn yaitu Civic Responsibility dimana dalam konteks ini negara memiliki tanggungjawab daalam memenuhi hak-hak warga negara. Van Metter \& Van Horn: Van metter \& Van Horn (Grindle, 1980: 6) menyatakan bahwa tugas implementasi adalah membangun jaringan yang memungkinkan tujuan kebijakan publik direalisasikan melalui aktivitas instansi pemerintah yang melibatkan berbagai pihak yang berkepentingan. Dari definisi diatas tersebut dapat diketahui bahwa implementasi kebijakan menyangkut tiga hal, yaitu: kebijakan, b) adanya aktivitas atau kegiatan pencapaian tujuan, dan c) adanya hasil kegiatan. Berikut di bawah ini ini akan diuraikan unsurunsur implementasi kebijakan PKH Lansia di Kecamatan Jebres Surakarta:

\section{a. Adanya Tujuan/ Sasaran kebijakan \\ Implementasi PKH Lansia di} Kecamatan Jebres Surakarta sudah memiliki standard dan sasaran yang jelas sesuai dalam buku pedoman PKH dimana target dari program PKH Lansia adalah warga lansia yang telah berusia 70 tahun ke atas dan masuk dalam kualifikasi keluarga penerima manfaat (KPM) atau masuk kategori miskin. Penerima PKH Lansia di Kecamatan Jebres sendiri ada 523 lansia. Sesuai petunjuk dalam buku pedoman $\mathrm{PKH}$, secara umum Program Keluarga Harapan (PKH) memiliki tujuan yaitu untuk meningkatkan aksesibilitas terhadap pelayanan pendidikan, kesehatan, dan kesejahteraan sosial dalam mendukung tercapainya kualitas hidup keluarga miskin. Dengan adanya PKH dalam jangka pendek diharapkan dapat mengurangi beban pengeluaran keluarga miskin serta memutus rantai kemiskinan dalam jangka panjang. Secara khusus, PKH memiliki tujuan untuk:

1) Meningkatkan konsumsi keluarga peserta PKH;

2) Meningkatkan kualitas kesehatan peserta PKH;

3) Meningkatkan taraf pendidikan anak-anak peserta $\mathrm{PKH}$;

4) Mengarahkan perubahan perilaku positif peserta $\mathrm{PKH}$ terhadap pentingnya kesehatan, pendidikan, dan pelayanan kesejahteraan sosial; 
5) Memastikan terpeliharanya taraf kesejahteraan sosial.

Dengan adanya program PKH Lansia diharapkan warga lansia miskin dapat memenuhi kebutuhan dasar hidupnya, selain itu dapat merubah perilaku mereka agar lebih peduli terhadap arti pentingnya kesehatan. Dengan adanya PKH Lansia diharapkan juga dapat menumbuhkan kepedulian sosial para keluarga yang merawat lansia miskin untuk menjaga dan merawat para lansia yang menjadi anggota keluarganya.

\section{b. Adanya Kegiatan}

Pada pelaksanaan PKH Lansia terdapat beberapa kegiatan yang dilakukan selama keberjalanan program tersebut sesuai yang tercantum di dalam buku pedoman PKH. Berikut ini adalah kegiatan yang dijalankan dalam pelaksanaan PKH Lansia di Kecamatan Jebres Surakarta:

\section{1) Penetapan peserta PKH (Targetting) \\ Kegiatan perdana dari} program PKH Lansia dimulai dari agenda penetapan peserta $\mathrm{PKH} /$ targetting. Pada kegiatan targetting ini akan ditentukan warga lansia mana yang berhak menerima bantuan sosial PKH Lansia. Sesuai dengan buku pedoman PKH, Lansia yang berhak menerima bantuan PKH adalah warga lanjut usia yang telah berusia 70 tahun ke atas dan masuk kategori warga miskin. Pendataan warga penerima PKH sendiri dilakukan oleh Badan Pusat Statistik (BPS) dimana dalam hal ini BPS memiliki kriteria tersendiri dalam menentukan kategori warga miskin. Setelah BPS melakukan pendataan maka data warga miskin tersebut diserahkan kepada UPPKH kota untuk ditindaklanjuti.

Setelah menerima data warga miskin dari BPS, maka UPPKH kota kembali melakukan verifikasi untuk mengecek dan memastikan apakah warga lansia tersebut benar-benar berhak mendapatkan bantuan sosial. Terkait hal ini UPPKH Kota menerjunkan pendamping $\mathrm{PKH}$ di tiap Kecamatan untuk melakukan survey di lapangan. Di Kecamatan Jebres ada sekitar 523 lansia penerima program $\mathrm{PKH}$.

\section{2) Sosialisasi}

Kegiatan kedua setelah dilakukan penetapan peserta adalah sosialisasi. Tujuan dari kegiatan sosialisasi adalah untuk memperkenalkan program $\mathrm{PKH}$ Lansia kepada warga Lansia penerima bantuan. Pada kegiatan sosialisasi ini dibahas mengenai hal-hal seperti: maksud dan tujuan PKH lansia, sasaran penerima PKH lansia, bantuan dan layanan kesehatan PKH lansia, pembentukan kelompok PKH, pertemuan kelompok (P2K2), verifikasi komitmen, dan sanksi. Pelaskanaan sosilisasi dilaksanakan di Kecamatan dimana dalam kegiatan ini turut dihadiri bapak Camat, perwakilan pihak puskesmas, serta lansia calon penerima bantuan progra PKH. Diharapkan dengan adanya kegiatan sosialisasi adalah agar pemerintah dapat mengkomunikasikan programnya kepada masyarakat sasaran agar nantinya program ini dapat berjalan sesuai dengan tujuan awal yang telah ditetapkan.

Sebelum menghadiri acara sosialisasi para warga lansai calon 
penerima bantuan PKH akan menerima Surat Undangan Pertemuan Awal (SUPA) yang dikirimkan oleh tim pendamping melalui Kelurahan, dimana SUPA tersebut berisi undangan untuk menghadiri acara sosialisasi tentang PKH di Kecamatan dan sifatnya adalah wajib. Dalam kegiatan sosialsiasi tersebut warga lansia calon penerima $\mathrm{PKH}$ juga diwajibkan untuk menandatangani surat perjanjian yang pada intinya adalah para penerima bantuan $\mathrm{PKH}$ berkomitmen untuk mentaati segala bentuk peraturan yang telah ditetapkan sebagai penerima bantuan PKH. Agenda sosialisasi sudah dijalankan waktu itu bertempat di tiap-tiap kantor Kecamatan yang ada di Kota Surakarta, total ada 12.120 keluarga penerima manfaat program PKH.

\section{3) Bantuan PKH Lansia}

Pada tahap ini, lansia yang menjadi sasaran program PKH berhak mendapatkan bantuan sosial sebagai instrumen penanggulangan kemiskinan dan sarana untuk meningkatkan taraf kesejahteraan sosial. Bentuk bantuan yang diberikan meliputi:

a) Bantuan layanan kesehatan berupa layanan posyandu lansia dan pemeriksaan gratis di Puskesmas;

b) Bantuan uang tunai sejumlah Rp2.000.000,00 per tahun yang cair setiap tiga bulan sekali;

c) Bantuan pangan berupa Bantuan Pangan Non Tunai (BPNT) yang berupa uang sejumlah Rp110.000,00 yang dapat dicairkan melaui E-Warung yang tersedia untuk ditukarkan dengan sembako berupa beras, minyak goreng, tepung, dan telur.

\section{4) Pertemuan Kelompok/ FDS}

Pertemuan Kelompok/

Family Development Session merupakan agenda rutin berupa pertemuan kelompok yang diadakan setiap bulan sekali dan sifatnya wajib bagi lansia penerima PKH namun kehadirannya dapat diwakilkan oleh anggota keluarganya. Tujuan dari adanya FDS ini adalah meningkatkan pengetahuan serta kesadaran lansia penerima PKH tentang arti pentingnya menjaga kesehatan, serta mengedukasi lansia tentang hak mereka untuk mengakses fasilitas kesehatan yang telah disediakan pemerintah seperti posyandu dan puskesmas. Para lansia penerima juga sudah rutin mengikuti FDS yang diselenggarakan setiap bulannya.

\section{5) Pendampingan}

Selain mendapatkan bantuan tunai dan pangan, para penerima $\quad \mathrm{PKH}$ juga mendapatkan layanan pendampingan dari tim pendamping $\mathrm{PKH}$. Dengan adanya pendampingan diharapkan tujuan dari adanya program PKH dapat tercapai secara optimal. Terkait hal ini pendamping $\mathrm{PKH}$ merupakan ujung tombak dalam pelaksanaan PKH dikarenakan pendamping PKH adalah unit yang secara langsung bertemu dan berinteraksi dengan para penerima program. Pendamping PKH memiliki tugas memastikan 
bantuan yang disalurkan Pemerintah benar-benar diterima oleh peserta dan dimanfaatkan sesuai dengan tujuan program tersebut. Selain itu, pendamping PKH juga sudah mengadakan mengadakan pertemuan kelompok/ FDS untuk memonitor keadaan penerima program $\mathrm{PKH}$ dan memberikan edukasi tentang pendidikan keluarga kepada seluruh penerima bantuan PKH dengan harapan para penerima bantuan ini dapat mengubah pola pikir dan pola perilakunya ke arah yang lebih baik. Pendamping juga terbuka dalam menerima pengaduan dari masyarakat terkait keberjalanan program PKH dengan membuka sebuah sistem pengaduan masyarakat di kantor sekretariat PKH sehingga masyarakat dapat melapor jika ada keluhan terkait pelaksanaan program $\mathrm{PKH}$.

\section{6) Verifikasi Komitmen}

Program Keluarga Harapan

(PKH) merupakan bantuan sosial yang sifatnya unik, hal ini disebabkan untuk mendapatkan bantuan, para penerima $\mathrm{PKH}$ juga diwajibkan untuk memenuhi kewajibannya sesuai dengan perauturan $\mathrm{PKH}$. Pada $\mathrm{PKH}$ Lansia penerima $\mathrm{PKH}$ diwajibkan untuk menghadiri kegiatan pertemuan kelompok/FDS yang diadakan setiap bulan sekali dan dianjurkan menghadiri kegiatan posyandu lansia. Terkait hal ini pendamping bertugas untuk melakukan verifikasi komitmen untuk memastikan kehadiran lansia pada kegiatan posyandu serta kegiatan FDS.
Hasil verifikasi komitmen di Kecamatan Jebres menunjukkan lansia penerma PKH sudah memenuhi kewajibannya seperti menghadiri pertemuan kelompok tiap bulan dan sudah memanfaatkan layanan kesehatan yang tersedia ketika memeriksakan kondisi kesehatannya baik di posyandu maupun puskesmas ketika akan berobat

\section{c. Adanya Hasil}

Implementasi PKH Lansia di Kecamatan terhadap pemenuhan hak sosial lansia di Kecamatan Jebres sudah berjalan dengan baik. Hal tersebut dapat dilihat dari terpenuhinya beberapa tujuan khusus PKH berikut ini.

1) Meningkatkan konsumsi keluarga peserta PKH: Dengan adanya bantuan PKH Lansia secara tidak langsung juga akan meningkatkan tingkat konsumsi lansia miskin peserta PKH di Kecamatan Jebres. Hal ini dikarenakan para peserta PKH Lansia juga akan tercover program Bantuan Pangan Non Tunai/ BPNT dimana setiap bulannya lansia penerima program PKH dapat mengakses bantuan pangan berupa sembako melalui EWarung yang tersedia di Kecamatan Jebres, total ada 15 EWarung di Kecamatan Jebres sebagai agen penyalur program bantuan pangan.

2) Meningkatkan kualitas kesehatan peserta PKH: Melalui program PKH Lansia, para lansia peserta PKH juga berhak mendapatkan layanan kesehatan yang telah disediakan Pemerintah, sebab kunjungan pemeriksaan kesehatan juga merupakan salah satu kewajiban yang harus dipenuhi 
sebagai peserta PKH Lansia. Selain itu, lansia peserta PKH juga akan tercover program JKN-KIS sehingga lansia peserta PKH dapat memeriksakan kondisi kesehatannya secara gratis di puskesmas mitra PKH.

3) Mengarahkan perubahan perilaku positif peserta PKH terhadap pentingnya kesehatan, pendidikan, dan pelayanan kesejahteraan sosial: Selain mendapatkan bantuan sosial, para lansia peserta PKH juga akan mendapatkan program pemberdayaan keluarga / Family Development Session. Melalui kegiatan ini, lansia penerima PKH akan mendapatkan edukasi tentang pentingnya kesehatan, pengelolaan keuangan keluarga, Perilaku Hidup Bersih dan Sehat, diharapkan keluarga miskin ini menjadi mandiri baik secara finansial maupun sosial.

4) Memastikan terpeliharanya taraf kesejahteraan sosial: Melalui program $\mathrm{PKH}$ Lansia diharapkan akan meningkatkan taraf kesejahteraan lansia penerima $\mathrm{PKH}$, lansia penerima PKH akan memperoleh bantuan tunai sejumlah Rp 2.000.000,00/tahun yang cair tiap triwulan. Diharapkan dengan bantuan tersebut dapat meringankan beban perekonomian keluarga lansia yang merawatnya dan memenuhi kebutuhan lansia tersebut.

\section{Faktor-faktor}

yang mempengaruhi implementasi PKH lansia di Kecamatan Jebres

Implementasi PKH Lansia di Kecamatan Jebres dipengaruhi beberapa faktor. Hal tersebut sesuai dengan teori proses implementasi Kebijkan yang dikemukakan oleh Van Metter dan Van Horn. Dalam model ini terdapat beberapa faktor yang mempengaruhi implementasi suatu kebijakan:

\section{Faktor Pendorong:}

\section{a. Sumber Daya}

Faktor Sumber Daya mempengaruhi keberhasilan suatu implementasi kebijakan. Manusia merupakan sumber daya yang terpenting dalam menentukan keberhasilan suatu implementasi. Selain itu, ada juga sumber daya finansial dan sumber daya fasilitas yang tidak kalah penting dalam menunjang keberhasilan suatu implementasi kebijakan. Pada implementasi kebijakan PKH Lansia sudah memiliki sumber daya yang berkualitas dan mencukupi untuk menjalankan program PKH. SDM dalam pelaksanaan $\mathrm{PKH}$ lansia di Kecamatan Jebres meliputi tim pendamping PKH yang berjumlah 13 orang dan berpendidikan S1. Dari segi fasilitas terdapat kantor sekretariat yang disediakan, alat tulis kantor, buku pedoman PKH, fasilitas kesehatan mitra PKH, E-Warung penyalur BPNT, sementara dari segi finansial pendanaan program $\mathrm{PKH}$ berasal dari APBN.

\section{b. Dukungan Publik}

Faktor Dukungan publik juga mempengaruhi keberhasilan suatu implementasi kebijakan. Suatu kebijkan akan berjalan dengan lebih mudah apabila mendapat dukungan dari masyarakat, sehingga target dari program yang dicanangkan pemerintah dapat tercapai. Adanya PKH Lansia di Kecamatan Jebres 
mendapat dukungan positif dari warga lansia penerima PKH Lansia.

Para lansia penerima $\mathrm{PKH}$ mendukung program ini dikarenakan dengan adanya program PKH lansia dapat membantu meringankan beban perekonomian mereka dan mengangkat perekonomian keluarga. Selain itu dengan bantuan PKH Lansia para lansia dapat mendapatkan edukasi tentang pentingnya menjaga kesehatan serta dapat memeriksakan kesehatannya di fasilitas kesehatan yang tersedia seperti posyandu lansia maupun puskesmas yang tersedia. Dengan adanya bantuan PKH mereka juga mendapatkan bantuan komplementaris lainnya seperti Kartu Indonesia Sehat (KIS) serta Bantuan Pangan Non Tunai (BPNT).

\section{c. Karakteristik Agen Pelaksana}

Keberhasilan implementasi suatu kebijakan tidak terlepas dari karakteristik yang dimiliki oleh badan pelaksana kebijakan. Badan pelaksana dapat berupa badan formal dan badan informal . Agustino (2008: 143) menyatakan bahwa pusat perhatian pada agen pelaksana meliputi organissasi formal dan organisasi informal yang akan terlibat dalam implementasi kebijakan. Agen pelaksana yang terlibat dalam implementasi PKH Lansia di Kecamatan Jebres meliputi UPPKH Kota Surakarta, Pendamping PKH di Kecamatan, posyandu lansia, Puskesmas, E-Warung sebagai agen penyalur bantuan pangan, Bank Himbara penyalur uang PKH. Agenagen tersebut memiliki tugas/fungsi masing-masing dan saling berkoordinasi satu sama lain untuk mewujudkan dari tujuan utama PKH.
Faktor Penghambat :

\section{a. Standard dan sasaran kebijakan}

Implementasi PKH Lansia di Kecamatan Jebres sudah memiliki standard dan tujuan yang jelas. Sasaran utama penerima PKH Lansia adalah lansia yang masuk kategori Keluarga Sangat Miskin dan berusia 70 tahun, di Kecamatan Jebres ada sekitar 523 lansia miskin penerima PKH. Meskipun dalam pelaksanaannya di lapangan masih ditemui kekurangan yaitu belum adanya sinkronisasi data kemiskin antara pemerintah pusat dengan pemerintah kota Surakarta.

\section{b. Komunikasi}

Komunikasi yang terjalin dalam pelaksanaan PKH Lansia di Kecamatan Jebres sudah berjalan, namun masih terbatas pada penerima bantuan saja, sementara masyarakat miskin non penerima PKH tidak mendapatkan sosialisasi, sehingga jika masih ada warga miskin yang belum menerima PKH tidak dapat mendaftarkan dirinya untuk mendapatkan bantuan sebab data penerima $\mathrm{PKH}$ adalah wewenang pusat.

\section{c. Disposisi}

Dari segi sistem pengaduan masyarakat sikap pelaksana untuk mengatasi persoalan masih rendah, masalah yang sering muncul di lapanan adalah masih banyaknya warga yang protes karena tidak terdata sebagai penerima $\mathrm{PKH}$, namun dari pendamping sendiri tidak bisa berbuat banyak sebab data penerima $\mathrm{PKH}$ adalah wewenang pusat. 


\section{Implementasi PKH Lansia dalam Perspektif Pendidikan Kewarganegaraan}

Pendidikan Kewarganegaraan mengkaji tentang Hak Asasi Manusia (HAM). Pendidikan kewarganegaraan (civic) yang hakikatnya juga sebagai pendidikan untuk mengenali dan menghayati hak-hak warganegara yang asasi (civil right) dengan tujuan agar setiap orang pada akhirnya dapat menyadari hak-haknya yang asasi, yang perlindungannya dijamin oleh undang-undang negara. Lebih lanjut, civic and human right education tidak hanya sebatas menyadari hak-haknya sendiri, tetapi diharapkan dapat pula akan mengembangkan empati, ialah kesadaran bahwa orang lain sebagai sesama warga atau sesama manusia memiliki hak yang harus dihormati. (Malian \& Marzuki: 2003, hlm 2-3).

Hak Asasi Manusia merupakan seperangkat hak yang melekat pada hakikat dan keberadaan setiap manusia sebagai makhluk Tuhan Yang Maha Esa dan merupakan anugeraah-Nya yang wajib dihormati, dijunjung tinggi, dan dilindungi oleh Negara, hukum, pemerintahan, dan setiap orang, demi kehormatan serta perlindungan harkat dan martabat manusia. HAM yang terkandung dalam konstitusi dapat disebut sebagai hak konstitusional warga negara. Menurut Prof. Jimly Asshiddiqie (2005: 152) hak konstitusional merupakan hak-hak yang dijamin oleh UUD RI 1945. Setelah amandemen, UUD 1945 lebih banyak mengakui bentuk-bentuk HAM sebagai hak konstitusional warga negara Indonesia. Hak konstitusional memuat ketentuan tentang hak sosial warga negara yang tercermin dalam beberapa pasal.
Implementasi PKH Lansia merupakan bentuk pemenuhan HAM dalam hal ini adalah pemenuhaan hak sosial bagi warga lanjut usia miskin. Ditinjau dari pemenuhan hak sosial, kebijakan Program Keluarga Harapan Lansia mencerminkan tanggung jawab Negara dalam hal ini pemerintah Indonesia dalam melindugi hak-hak kaum lanjut usia miskin dalam mendapatkan kehidupan yang sejahtera. Negara wajib memberikan jaminan sosial kepada waega lanjut usia sesuai yang diatur dalam pasal $28 \mathrm{H}$ ayat (3) UUD NRI 1945 yang menyatakan,"Setiap orang berhak atas jaminan sosial yang memungkinkan pengembangan dirinya secara utuh sebagai manusia yang bermartabat". Pasal ini menegaskan bahwa jaminan sosial merupakan hak bagi setiap warga negara termasuk warga lansia di dalamnya. Hal tersebut juga sesuai dengan konstitusi kita pada pasal 34 ayat 2 yang mengatakan, "Negara mengembangkan sistem jaminan sosial bagi seluruh rakyat dan memberdayakan masyarakat yang lemah dan tidak mampu sesuai dengan martabat kemanusiaan.

Pendidikan Kewarganegaraan memiliki tiga fungsi pokok sebagai wahana pengembangan warga negara yang demokratis, yakni: a) Civic Intelligence yaitu kecerdasan dan daya nalar warga negara yang baik dalam dimensi spiritual, rasional, emosional; b) Civic Responsibility yaitu kesadaran akan hak dan kewajiban sebagai warga negara yang bertanggungjawab; dan c) Civic Participation yaitu keikutsertaan warga negara dalam membantu dan memajukan negara. (dalam Winarno, 2013: 19). Berkaitan dengan hal 
tersebut, implementasi kebijakan PKH Lansia di Kecamatan Jebres mencerminkan ketiga aspek tersebut.

Bentuk Civic Intelligence dalam implementasi kebijakan PKH Lansia adalah ketika diadakannya kegiatan FDS (Family Development Session) yang diadakan setiap sebulan sekali. FDS merupakan suatu langkah terstruktur dan sistematis yang dilakukan oleh petugas pendamping PKH guna menciptakan masyarakat yang sadar tentang pentingnya aspekaspek kehidupan.

Civic Participation dalam implementasi kebijakan PKH Lansia meliputi adanya partisipasi dari lansia penerima PKH di Kecamatan Jebres dalam mendukung kegiatan $\mathrm{PKH}$, seperti melakukan kunjungan rutin ke posyandu lansia, kehadiran pada saat acara FDS, serta memanfaatkan fasilitas kesehatan puskesmas yang merupakan mitra PKH ketika akan berobat. Adanya partisipasi penyedia fasilitas kesehatan serta E-Warung, serta partisipasi pendamping $\mathrm{PKH}$ dalam upaya membantu masyarakat penerima PKH agar keluar dari zona kemiskinan dan mandiri baik secara finansial maupun sosial.

Civic Responsibility dalam implementasi kebijakan PKH Lansia dapat dilihat sebagai sebuah bentuk tanggungjawab Pemerintah Indonesia untuk meningkatkan taraf kesejahteraan sosial warga lansia miskin. Hal tersebut sesuai dengan bunyi pasal 7 UU No. 13 Tahun 1998 tentang kesejahteraan sosial lansia yang berbunyi" "Pemerintah bertugas mengarahkan, membimbing dan menciptakan suasana yang menunjang bagi terlaksananya upaya peningkatan kesejahteraan sosial lanjut usia". Oleh sebab itu melalui Permensos No. 01 Tahun 2018 Pemerintah membuat kebijakan Program Keluarga Harapan dimana salah satu komponen penerima bantuannya adalah warga lansia miskin.

\section{KESIMPULAN}

$\begin{array}{lrr}\text { Dari } & \text { penelitian yang telah } \\ \text { dilaksanakan } & \text { peneliti } & \text { tentang } \\ \text { implementasi } & \text { PKH } & \text { terhadap }\end{array}$ pemenuhan hak sosial warga lansia miskin di Kecamatan Jebres dapat disimpulkan bahwa Implementasi kebijakan pkh lansia sudah berjalan sesuai SOP sehingga hak sosial dari warga lansia miskin di Kecamatan Jebres dapat terpenuhi. Implementasi pkh lansia di Kecamatan Jebres meliputi: Targetting, sosialisasi, pembayaran bantuan, pertemuan kelompok, pendampingan, dan verifikasi komitmen. Bentuk pemenuhan hak sosial lansia miskin di Kecamatan Jebres meliputi: Hak pangan melalui program BPNT, hak kesehatan melalui pelayanan kesehatan di posyandu/ puskesmas, serta hak kesejhteraan sosial melalui bantuan uang tunai dengan nominal Rp 2.000.000,00/tahun. Sementara faktor-faktor yang mempengaruhi implementasi pkh lansia di Kecamatan Jebres meliputi: Faktor pendukung: Sumber Daya, Dukungan publik, Karakteristik agen pelaksana. Sementara faktor penghambat: Komuniksi, sasaran, dan disposisi.

\section{SARAN}

Berdasarkan kesimpulan dan implikasi yang dipaparkan di atas, maka penulis mengemukakan saran sebagai berikut: 
1. Bagi Pemerintah Pusat dan daerah agar segera membuat sebuah sistem data kemiskinan yang sinkron sehingga pelaksanaan $\mathrm{PKH}$ dapat berjalan efektif

2. Bagi Pemkot Surakarta agar membuat perda lansia sebab menurut UU No. 23 Tahun 2014 penanganan kesejahteraan lansia adalah tugas pemerintah daerah.

3. Bagi pendamping $\mathrm{PKH}$ untuk lebih meningkatkan lagi koordinasi dengan pihakpihak lain seperti posyandu lansia, puskesmas, serta EWarung dalam upaya meningkatkan kesejahteraan sosial warga lansia.

1. Bagi warga lansia penerima bantuan PKH untuk lebih sadar lagi dalam menjaga kesehatan dengan memanfaatkan fasilitas kesehatan yang tersedia, seperti: posyandu dan puskesmas 


\section{DAFTAR PUSTAKA}

Abdul Azis Wahab \& Sapriya. (2011). Teori dan Landasan Pendidikan Kewarganegaraan. Bandung: CV Alfabeta

Agustino, Leo. (2008). Dasar-dasar Kebijakan Publik. Bandung: Alfabeta

LexyJ. Moleong . (2007). Metodologi Penelitian Kualitatif. Bandung: PT. Remaja Rosdakarya

Malian, S. \& Marzuki, S, (2003). Pendidikan Kewarganegaraan dan Hak Asasi Manusia. Yogyakarta: UII Press Yogyakarta

Miles,B.B., dan A.M. Huberman. (1992). Analisa Data Kualitatif. Jakarta: UI Press

Sjafari, Agus. (2014). Kemiskinan dan Pemberdayaan Kelompok. Yogykarta: Graha Ilmu

Sri Palupi. (2010). Hak Ekosob (Materi Training HAM). Makassar

Sugiyono. (2012). Metode Penelitian Pendidikan,Pendekatan Kuantitatif, Kualitatif dan $R \& D$. Bandung: Alfabeta

Suharto, Edi. (1997). Pembangunan, Kebijakan Sosial dan Pekerjaan Sosial: Spektrum Pemikiran. Bandung: Lembaga Studi Pembangunan-STKS.

Suparlan, Parsudi. (1995). Kemiskinan di Perkotaan. Jakarta: Yayasan Obor Indonesia

Suryawati. (2004). Teori Ekonomi Mikro. Yogyakarta: UPP AMP YPKN

Syawie, M. Kemiskinan dan Kesenjangan Sosial. Informasi: Kajian Permasalahan Sosial dan Usaha KESEJAHTERAN Sosial

Widodo, Joko. (2008). Analisis Kebijakan Publik. Malang: Bayumedia Publishing Winarno. (2009). Kewarganegaraan Indonesia Dari Sosiologis Menuju Yuridis. Bandung: Alfabeta

Winarno. (2013). Pembelajaran Pendidikan Kewargnegaraan: PT Bumi Aksara Winarno, Budi. (2014). Teori dan Proses Kebijakan Publik. Yogyakarta: Media Pressindo 